International Journal of Current Advanced Research

ISSN: O: 2319-6475, ISSN: P: 2319 - 6505, Impact Factor: SJIF: 5.995

Available Online at www.journalijcar.org

Volume 6; Issue 4; April 2017; Page No. 3329-3332

DOI: http://dx.doi.org/10.24327/ijcar.2017.3332.0264

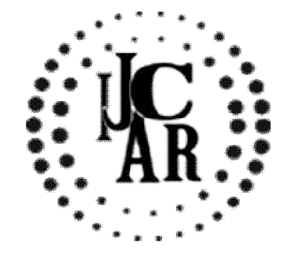

Research Article

\title{
CONSCIOUS SEDATION IN PEDIATRIC DENTISTRY-A QUESTIONNAIRE SURVEY
}

\author{
Abijeth.B and Anitha Roy*
}

Saveetha Dental College \& Hospitals, Chennai - 600077, Tamil Nadu, India

\begin{tabular}{l}
\hline A R T I C L E I N F O \\
\hline Article History: \\
Received $20^{\text {th }}$ January, 2017 \\
Received in revised form $10^{\text {th }}$ February, 2017 \\
Accepted $17^{\text {th }}$ March, 2017 \\
Published online $28^{\text {th }}$ April, 2017 \\
\end{tabular}

Key words:

Conscious sedation, Pediatric dental patients, Pediatric dentist, Anxiety management, Nitrous oxide.

\begin{abstract}
A B S T R A C T
Aim - To assess the usage of conscious sedation by pediatric dentists and postgraduates

Materials and Methods-A pretested interviewer administered questionnaire was framed regarding the suggestion of drug, its usage, preferred route of administration and common complications encountered and it was circulated among 125 pediatric dentists and postgraduates in private dental colleges.

Result-Various agents were used among which nitrous oxide being more common (62\%), followed by midazolam (26\%), sevofluorane $(6 \%)$ and isofluorane $6 \%)$. Inhalational route of administration was used predominantlyused $(82 \%)$. Common side effects encountered include nausea (40\%), vomiting (40\%), drowsiness (12\%) etc.

Conclusion-Pharmacological agents may be used as a complement to behavioral techniques to assist in the management of anxiety in some pediatric dental patientsso that they can maintain their oral hygiene in a good and proper manner.
\end{abstract}

Copyright $@ 2017$ Abijeth.B and Anitha Roy. This is an open access article distributed under the Creative Commons Attribution License, which permits unrestricted use, distribution, and reproduction in any medium, provided the original work is properly cited.

\section{INTRODUCTION}

Current understanding of pediatric oral health includes absence of dental fear and anxiety as well as healthy oral structures with the aim of forming the basis for good oral health throughout life. This implies two main dimensions in pediatric oral care which is to keep the oral environment healthy and to keep the patient capable of, and willing to utilize the dental service. ${ }^{[1]}$ It is widely recognized that the level of caries in children of various nations has dropped substantially over the last few decades. Unfortunately a significant proportion of these children still have caries which remains untreated. This represents a significant problem, if dentine caries is left it will usually lead to pain and sepsis which can often only be managed by extraction or extensive restoration of the affected teeth. ${ }^{[2]}$ Either conscious sedation or pre-medication with pharmacological agents is often recommended to children who are particularly fearful or anxious or for whom a disability prevents their being able to cooperate ,during the dental treatment. ${ }^{[3,4]}$ The treatment and alleviation of pain is a basic human right that exists regardless of age and demands treatment for this reason alone. Therefore all children should expect painless, high quality dental care. ${ }^{[5]}$ Sedation is required for some pediatric patients in order for the dentists to be able to deliver high quality, pain-free dental care. Sedation is usedfor pain control in form of local anesthesia, and for behaviormanagement ${ }^{[2] .}$

*Corresponding author: Anitha Roy

Saveetha Dental College \& Hospitals, Chennai - 600077,

Tamil Nadu, India
Sedation is the production of a depressed state involving a lack of total consciousness. In sedation, the protective pharyngeal and laryngeal reflexes are not dulled, so the patient can maintain his or her own airway. In this sedated state, the functional activity of the higher centre of the central nervous system is reduced without distortion of the vital functions. ${ }^{[3]}$

The goal ofconscious sedation is to ensure safety by improving physiologic monitoring. ${ }^{[6]}$ Various sedative agents and combinations have been used to reduce the anxiety and fear associated with dentistry, butvariable results have been obtained with respect to efficacy and safety. The fact that no single sedative agent has achieved universal acceptance suggests that each agent has disadvantages. ${ }^{[7]}$ Sedation becomes optimally effective only when there is some rapport between the dentist and patient.

The agents used should be rapidly and reliably effective with absorption and uptake fast enough to allow treatment to begin within a very short time of administration. It should have adequate duration of effect as well as rapid recovery. ${ }^{[3]}$ Many drugs are available for use as sedatives such as Nitrous oxide, ${ }^{[8-12]}$ Midazolam, ${ }^{[13-17]}$ Isofluorane and Sevofluorane. ${ }^{[18]}$ Sedation is indicated in Children with low coping ability, Behavior management problems, Dental fear and anxiety, odontophobia, Mental retardation, General disorders, psychiatric conditions, Emergency treatment, Moderate to large and complicated treatment needs. Sedation of children below the age of 1 year is said to be contraindicated, and hardly never relevant in the dental setting. ${ }^{[1]}$ As conscious 
sedation is one of the integral part of the pediatric dental care, this questionnaire survey was carried out.

\section{MATERIALS AND METHODS}

A pretested interviewer administered questionnaire was framed regarding the suggestion of drug, its usage, preferred route of administration and common complications encountered and it was circulated among the pedodontists and postgraduate students in the department of pedodontics of various private dental institutions. 125 pedodontists and postgraduate students participated in the questionnaire survey and they gave their opinion regarding the conscious sedation based on their clinical experience. The data collected from these 125 pedodontists and post graduate students of the same department were then statistically analyzed to generate appropriate results regarding the questionnaire study.

\section{RESULTS}

Based on the stastical analysis, $62 \%$ of the pedodontists and the postgraduate students prefer nitrous oxide for conscious sedation during their dental treatment. It is most commonly used drug and it is preferred by large number of the pediatric dentist population. ${ }^{[8,10,11]} 26 \%$ of the dentists prefer Midazolam to control their pediatric patients, whereas $6 \%$ of them prefer Sevofluorane and other $6 \%$ prefer Isofluorane. (Figure 1)

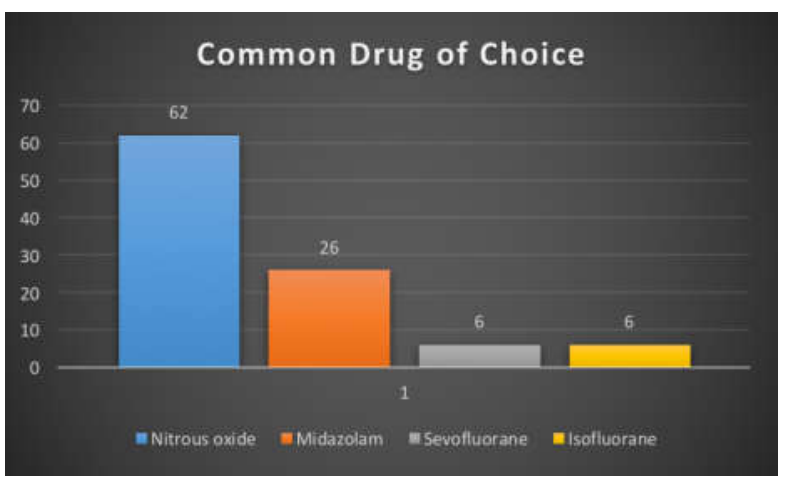

Figure 1 Common drug of Choice

The Most prevalent route of administration of the sedative drug used. $82 \%$ of the drug was administered by inhalation method whereas $18 \%$ of the drug was administered by intravenous route. The pediatric dentist also mentioned that during administration of the drug assistance from specialized anesthetist was also taken so that to increase the efficacy of the sedative drug and to maintain the vital signs of the patient in a safer manner.(Figure 2)

\section{Route of administration}

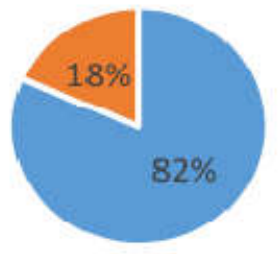

- Inhalational

- Intravenous

Figure 2 Preferred route of administration of the drug
The number of pediatric dentist who have attended any training program or have pursued any special course regarding the sedative drugs during or after their postgraduate studies. In that $92 \%$ of the population have attended the program and have better knowledge in handling the sedative drugs when compared to that $8 \%$ of the population who haven't attended any specialized programme.(Figure 3)

\section{Knowledge of sedation drugs by attending training programme}

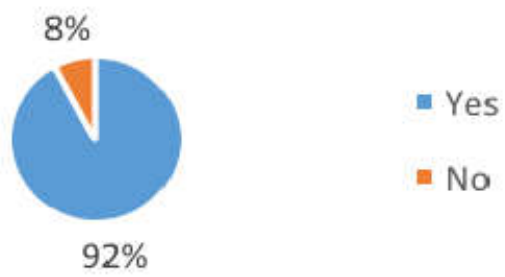

Figure 3 Knowledge about the sedation drugs used byattending training programme or any specialized course.

Various types of complications encountered during after the sedative process. $40 \%$ of the patient's complaint about nausea and vomiting and $12 \%$ of the patients experience post operative sleepiness. In $6 \%$ of the patients there is diffusion hypoxia and there $2 \%$ of chance for failure of anesthesia to happen.(Figure 4)

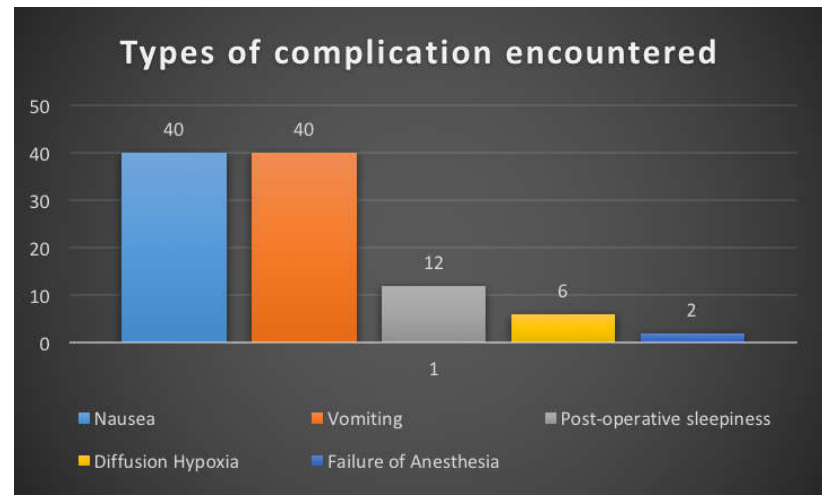

Figure 4 Various types of complications encountered

\section{DISCUSSION}

The majority of studies involved sedation in children less than 6 years of age, because this age range belongs to a 'precooperative' group. Treatment needs and management of children will vary as they grow and develop. ${ }^{[2]}$

The findings indicated that the over-whelming majority of practitioners have Nitrous oxide in their offices.Nitrous oxide was first used as an anesthetic agent in dentistry in December 1844 by Horace Wells. Nitrous oxide is a popular pharmacologic agent used either alone or in combination with other sedatives. ${ }^{[8,9]}$ Wes McCann and Stephen Wilson conducted a study in 1996 and Significant results were obtained in the behavior management of the pediatric patients with the use of nitrous oxide.

Nitrous oxide has analgesic, sedative and hypnotic properties. ${ }^{[3]}$ The drug have various advantages including 
rapid onset of action and recovery ( $2-3 \mathrm{~min}$ ), wide range of safety, ease of dose control, It doesn't cause any irritation to the respiratory tract and has a limited physiological effects.Nitrous oxidehas a CNS depressant action. It also causes minor depression in cardiac output while peripheral resistance is slightly increased, thereby maintaining the blood pressure. ${ }^{[10,11]}$ This is of particular advantage in treating patients with cerebrovascular system disorders. It causes minimal impairment of any reflexes, thus protecting the cough reflex. ${ }^{[12]}$ Diffusion hypoxia may occur during the termination of nitrous oxide. However, it is recommended that the patient receives $100 \%$ oxygen for 3-5 minutes at the termination stage to prevent this possibility. Proper administration can give a better conscious sedation without any complication. Midazolam is also preferred for sedating the pediatric patients which was used in 1975 by Walser and Fryer. ${ }^{[13]}$ Midazolam is good anxiolytic, sedative, hypnotic, anticonvulsant, muscle relaxant. It also have good anterograde amnesic effects and is highly lipophilic. ${ }^{[14-17]}$ This maybe the reason for its preferential use among pedodontists.

Oral administration of Midazolam is done for short dental procedures. ${ }^{[15]}$ But oral Midazolam has a disagreeable taste and patients may refuse to swallow. Though intravenous administration of Midazolam is more effective it is not preferred for pediatric patients. Intranasal Midazolam offered significant advantages, where the administration is simple, painless and the action is seen within $10 \mathrm{~min} .^{[15]}$ Similar method was stated by Ari Kupietzky on his study done in 1993. It has all the advantages of IV administration without the disadvantages of pain and fear associated with intravenous injections. However its slight decline of use in the study compared to nitrous oxide, is maybe due to its unavailability of preparation. ${ }^{[15]}$

Sevoflurane, first used in $1971,{ }^{[18]}$ and Isofluoranehad rapid onset and recovery times, amnesic effect, some analgesic effect and was easily titratable. They can be used for sedation in combination with nitrous oxide. However based on the study, its use was limited and it maybe due Odourintolerance, MalignantHyperthermia and moreover its not economic. ${ }^{[18]}$

\section{CONCLUSION}

Overall goal of conscious sedation in pediatric dentistry is to provide a pain free treatment and to relieve the fear and anxiety of the pediatric patients so that the patientfeels comfortable in the dental environment and willingly comes back to the clinic for regular checkups without any reluctance.The conscious sedation could increase the success rate of the treatment with ease of operation for the dentist while performing the dental procedure.

\section{References}

1. A.-L. Hallonsten, B. Jensen, M. Raadal, J. Veerkamp, M.T. Hosey, S. Poulsen. EAPD guidelines on sedation in paediatric dentistry. Pediatric Dentistry. A clinical approach. Copenhagen: Munksgaard, 2001: 226-8.

2. Matharu L, Ashley PF. Sedation of anxious children undergoing dental treatment. Cochrane Database of Systematic Reviews 2006, Issue 1. Art. No.: CD003877. DOI: 10.1002/14651858.CD003877.pub3.

3. M. O. Folayan, A. Faponle \& A. Lamikanra. A review of the pharmacological approach to the management of dental anxiety in children. International Journal of Paediatric Dentistry 2002; 12: 347-354.

4. Joseph P. Cravero, MD, and George T. Blike, MD. Review of Pediatric Sedation. International Anesthesia Research Society, Anesth Analg 2004; 99:1355-64.

5. HOSEY, M. T. Managing anxious children: the use of conscious sedation in paediatric dentistry. International journal of paediatric dentistry Volume 12(5) September 2002; 359-372

6. Michael F. Hasty, MS William F. Vann, Jr., Diane C. Dilley, Jay A. Anderson.Conscious sedation of pediatric dental patients:an investigation of chloral hydrate, hydroxyzine pamoate,andmeperidine vs. chloral hydrate and hydroxyzine pamoate. The American Academy of Pediatric DentistryVolume 13, Number 1, 10-19

7. JamesA.Roelofse, ${ }^{*}$ LouisR.Louw, and PieterG.Roelofse. Double Blind Randomized Comparison of OralTrimeprazine Methadone and Ketamine Midazolam for Sedation of Pediatric Dental Patients for Oral Surgical Procedures. American Dental Society of Anesthesiology 1998 AnesthProg45:3-11

8. Stephen Wilson. A survey of the American Academy of Pediatric.Dentistry membership: nitrous oxide and sedation.American Academy of Pediatric Dentistry. 1996 Pediatric Dentistry - 18:4, 287-293

9. Stephen Wilson, Kelly Farrell, Ann Griffen, Dan Coury. Conscious sedation experiences in graduate pediatric dentistry programs. American academy of pediatric dentistry. Pediatric dentistry 2001, 23:3 307314

10. Wes McCann, Stephen Wilson, Peter Larsen, Bill Stehle.The effects of nitrous oxide on behavior and physiological parameters during conscious sedation with a moderate dose of chloral hydrate and hydroxyzine. American academy of pediatric dentistry. Pediatric dentistry 1996, 18:1, 35-41

11. PattarawadeeLeelataweewud, William F. Vann, Diane C. Dilley, Warner J. Lucas.

12. The physiological effects of supplemental oxygen versus nitrous oxide/oxygen during conscious sedation of pediatric dental patients.American academy of pediatric dentistry. Pediatric dentistry 2000, 22:2, $125-$ 133

13. Paterson SA, Tahmassebi JF. Pediatric dentistry in the new millennium: Use of inhalation sedation in pediatric dentistry. Dent Update 2003; 30(7):350-6, 358.

14. Armin Walser, Rodney I. Fryer, Louis Benjamin. Imidazo [1,5-.alpha.][1,4] benzodiazepines. US Patent 4166185, issued to Hoffmann-LaRoche Aug 28, 1979.

15. Daniel A. Haas, ${ }^{*}$ Stephen A. Nenniger, Rebecca Yacobi,* Jose G. Magathan, Helen A. Grad,* Peter E. Copp, ${ }^{*}$ and Melvin D. Charendoff*. A Pilot Study of the Efficacy of Oral Midazolam for Sedation in Pediatric Dental Patients.American Dental Society of Anesthesiology. AnesthProg1996 43:1-8

16. Ari Kupietzky, Milton I. Houpt. Midazolam: a review of its use for conscious sedation of children. Pediatric Dentistry: July/August 1993 - Volume 15, Number 4 237-241

17. John E. Nathan, Kaaren G. Vargas. Oral midazolam with and without meperidine for management of the 
difficult young pediatric dental patient: a retrospective study. Pediatric Dentistry 2002 - 24:2, 129-138.

18. Thomas Silver, Carolyn Wilson, Michael Webb. Evaluation of two dosages of oral midazolam as a conscious sedation for physically and neurologically compromised pediatric dental patients.Pediatric Dentistry: September/October 1994 - Volume 16, Number 5 350-359.
19. Nicola Ross, Natalie Drury. Conscious sedation with Sevofluorane.Anesthesia tutorial of the week 188. 19 July 2010; p1-5

\section{How to cite this article:}

Abijeth.B and Anitha Roy (2017) ' A Conscious Sedation In Pediatric Dentistry-A Questionnaire Survey', International Journal of Current Advanced Research, 06(04), pp. 3329-3332.

DOI: http://dx.doi.org/10.24327/ijcar.2017.3332.0264 